\title{
Empirical Analysis of Influencing Factors in Collaboration of Primary Industry and Tertiary Industry in Dujiangyan City, Sichuan Province, China
}

\author{
Qizhi Yang \\ College of Tourism, Sichuan Agricultural University \\ Chengdou 611830, China \\ Tel: +86-28-8711-5330
}

Fuhui Yan

College of Economic Management, Sichuan Agricultural University

Chengdu 610000, Sichuan, China

Feng Ye (Corresponding author)

College of Economic Management, Sichuan Agricultural University

Chengdu 610000, Sichuan, China

E-mail: yefengjust106@126.com

Received: May 16, 2011

Accepted: July 13, 2011 Published: January 5, 2012

doi:10.5430/ijba.v3n1p84

URL: http://dx.doi.org/10.5430/ijba.v3n1p84

\begin{abstract}
Collaborative development of the thrice industrial is an important means for change of the economic development pattern on the basis of following the rule of industrial structure vicissitude. As an important water source in Chengdu City and an important ecological preservation area which has abundant tourism resources, industrial development of this region is relatively stable. It is a significant task of the municipal government of Dujiangyan to develop the primary industry and the tertiary industry in a collaborative way, which has great significance to effectively resolve the "three rural" issues in Dujiangyan and to promote social and economic development of Dujiangyan. This article makes sorting on important factors influencing the primary industry and tertiary industry in Dujiangyan through an empirical analysis and puts forward corresponding policies and suggestions.
\end{abstract}

Keywords: Primary Industry and Tertiary Industry, Collaboration, Factor

Implementation of industrial collaboration is a necessary requirement for industrial structure adjustment and economic growth pattern. It was pointed out in the report of the $17^{\text {th }}$ CPC National Congress in 2007, the way to accelerate changing the economic growth pattern and facilitate optimization and upgrading of industrial structure has to be transferred from driving by the secondary industry to collaborative driving by the secondary industry and the tertiary industry, which reveals the internal correlation between industrial structure and economic development and also discloses profoundly the relationship of interaction between different industries. In the mean time, in the current economic development, reinforcement and growth of the secondary industry adds up to pressure in energy resources. Furthermore, high consumption of energy, high consumption and high pollution also make the ecological environment unbearable, which gives rise to increasing governance cost. Meanwhile, backwardness of development of the tertiary industry goes against alleviation of the employment pressure, which, in return, is to the disadvantage of stability of the economic society. (An Shiyin, 2007) Hence, on the basis of following the rule of industrial structure adjustment and vicissitude, collaborative development of the industries has become an important means to facilitate economic development and offers a new train of thought for optimization and upgrading of industrial structure, which is also an important duty of the government.

Since Dujiangyan has the particular status of resources, such as, an important water supply area for Chengdum, an important ecological protection area and having abundant and advanced tourism resources, the municipal government of Dujiangyan has not vigorously developed industry according to resource endowment in economic development of 
Dujiangyan, but, instead, keeps the industrial development at a relatively stable level. As is shown in Figure 1, the secondary industry of Dujiangyan began to exhibit a mild and yet declining developmental trend. Collaborative development of the primary industry and the tertiary industry is an important task of the municipal government of Dujiangyan, which has great significance to effectively resolve the "three rural" issues in Dujiangyan and promote social and economic development of Dujiangyan City. In the realistic economic development of Dujiangyan City, what is the most important factor affecting collaboration between the primary industry and the tertiary industry is of great significance to make pertinent policies.

$<$ Figure 1 about here $>$

\section{Employment of Analysis Method}

From the analysis of collaboration between the compound system of the primary industry and the tertiary industry in Dujiangyan City in Section Four in the previous paper and the analysis result, it can be found that a benign interactive and coordinated relationship has not been formed in the developmental process of the primary industry and the secondary industry in Dujiangyan City. The result of collaboration calculated in this paper is closely connected with the evaluation indicator system established in the previous paper in that degree of collaboration is influenced by these indicators, namely, order parameters, while each indicator functions differently in the process of collaborative development of the primary industry and the tertiary industry. Hence, it is necessary to analyze the influence of each indicator on degree of collaboration between the primary industry and the tertiary industry. There are quite a lot of methods to analyze the influencing factors, such as, regression analysis, including linear regression, multi-factor regression, single-factor regression, stepwise regression, non-stepwise regression and so on, sensitivity analysis and grey correlation, etc. Although regression analysis is a popular method, it requires a large quantity of data. Otherwise, it is unlikely to discover its rule, which is inconsistent with the quantity required in this paper. Hence, this method is abandoned. Sensitivity analysis is often used to study uncertain factors, mixed with artificial and subjective hypothesis, which is inconsistent with certain indicators in this paper. Therefore, this paper employs Grey Correlation Analysis to make a systematic analysis, a quantified analysis of the developmental trend of the dynamic process. Grey Correlation Analysis makes a comparison between the geometrical relationship of relevant statistical data of the development and change system at different stages and makes quantitative description and comparative analysis to determine superior and inferior factors influencing the system development. This has great connection with the research content of this paper, and is thus employed.

\section{Grey Correlation Model}

Grey Correlation Model was initiated by Professor Deng Julong and was proposed for the first time by Professor Deng Julong in his article entitled "Control Problem in Grey System" that was published in 1982. (Deng Julong, 1999) He classified information into white, black and grey information. White stood for completely explicit information, black stood for completely implicit information and grey was in-between, namely, partly explicit information and partly implicit information. This theory regards as the research object the "small sample" in which "part of information is known and part of information is unknown" and uncertain system of "poor information" and seeks for valuable influencing factors through "known information" to achieve effective control over similar behaviors. Grey Correlation Analysis is a sort of multi-factor statistical analysis method, which makes a comparison between the geometrical relationship of relevant statistical data of the development and change system at different stages and makes quantitative description and comparative analysis to determine superior and inferior factors influencing the system development. The basic idea of Grey Correlation Analysis is to make an analysis and comparison of geometric shapes between several curves to judge that the more similar the geometric shape, the more similar the trend of the developmental change and the larger the correlation degree, whereas the smaller.

Establishment of the model is as below:

Step one: to determine analysis data column sequence and to set up raw data reference series (mother sequence) and comparative series (subsequence).

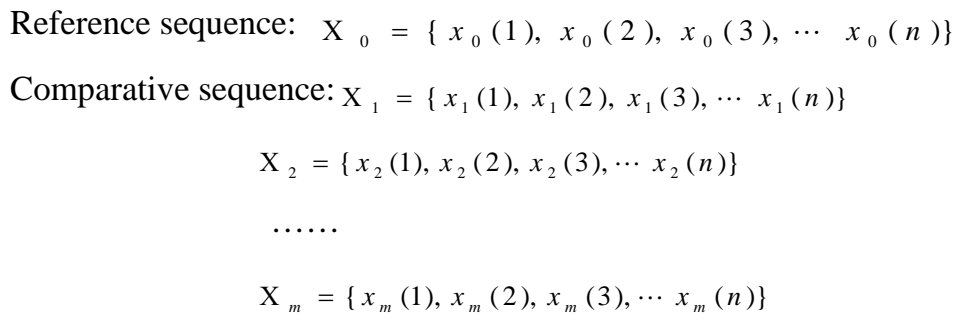


Step two: to make dimensionless calculation of averaging method or initial value method on raw data.

Step three: to calculate the difference between the reference sequence $X_{0}(k)$ and the comparative sequence $X_{m}(k)$.

$$
\begin{gathered}
\Delta_{i}=\left|\mathrm{X}_{0}(k)-\mathrm{X}_{m}(k)\right|=\left(\Delta_{1}(1), \Delta_{1}(2), \cdots, \Delta(n)\right) \\
\Delta_{i}=\left|\mathrm{X}_{0}(k)-\mathrm{X}_{m}(k)\right|=\left(\Delta_{2}(1), \Delta_{2}(2), \cdots, \Delta_{2}(n)\right) \\
\quad \cdots \cdots \\
\Delta_{i}=\left|\mathrm{X}_{0}(k)-\mathrm{X}_{m}(k)\right|=\left(\Delta_{n}(1), \Delta_{n}(2), \cdots, \Delta_{n}(n)\right)
\end{gathered}
$$

Step four: to get the minimal value and the maximum value.

Step five: to get the correlation coefficient, and the computational formula to get the correlation coefficient is as below:

$$
r(x(k), x(k))=\frac{\min _{i} \min _{k}\left|x_{0}(k)-x_{i}(k)\right|+\xi \max _{i} \max _{k}|x(k)-x(k)|}{\left|x(k)-x_{i}(k)\right|+\xi \max _{i} \max _{k}\left|x_{0}(k)-x_{i}(k)\right|}
$$

Where, $\xi$ is the resolution ratio, which is usually selected between 0 and 1 . The resolution ratio of 0.5 is selected in this paper.

Step six: to calculate the relevancy and the computational formula to get the relevancy is as below:

$$
r\left(\mathrm{X}_{0}, \mathrm{X}_{i}\right)=\frac{1}{N} \sum_{i=1}^{N} r\left(x_{0}(k), x_{i}(k)\right)
$$

\section{Grey Correlation Analysis of Influencing Factors}

\subsection{Explanation of Variables}

In combination of the actual situation of Dujiangyan, we set up the following evaluation indicator system in collaborative development of the primary industry and the tertiary industry in Dujiangyan City.

$<$ Table 1 about here>

\subsection{Explanation of Indicators}

For study of collaborative development of the system of the primary industry and the tertiary industry in Dujiangyan and establishment of a collaborative model appropriate for the collaborative development, we have to select suitable indicators according to particular resource endowment and climate features of the region in the process of the study for the purpose of actually and accurately reflecting developmental condition of industries within the region and providing assistance for the government to carry out appropriate industrial policies.

\subsubsection{Ratio of Value Added of the Industry to GDP}

Ratio of value added of the industry is able to reflect the industrial development scale and speed of a region and study of industrial collaborative development can't go without the indicator of value added of the industry. A larger output value indicates that the economic development of the region depends on this industry, but the development scale and speed of other industries should also not be neglected. Only when proportion of the three industries is developed in a collaborative way, is it likely to better facilitate rapid development of the regional economy.

\subsubsection{Ratio of Employees in the Industry}

Ratio of employees in the industry is able to reflect the benefit and quality of the industrial development. Development of any industry can't go without industrious labor of human being. The better the benefit and quality of development of the industry, the more likely it is to attract and absorb more labor forces, which is helpful for optimization of the employment structure and is an indispensable and important indicator to study collaborative development of the industries.

\subsubsection{Amount of Investment of Fixed Capital in the Industry}

Amount of investment of fixed capital in the industry refers to the amount of work in constructing and purchasing fixed capital activities that are expressed in the monetary form. This is an overall indicator that reflects scale, speed, proportion relationship and usage direction of fixed capital investment. Investment in an industry discloses the developmental prospect of the industry at a certain stage and the orientation of industrial support from the government and also reveals the developmental benefit and quality of the industry at the previous stage. This helps the enterprises to determine industrial development direction, expand employment space and, meanwhile, direct the production work of farmers in that it can better direct employment orientation of rural surplus labor force. 


\subsubsection{Output Value of Agriculture, Forestry, Animal Husbandry and Fishery}

Accounting scope of the output value of agriculture, forestry, animal husbandry and fishery refers to the sum of the quantity of value of products in agriculture, forestry, animal husbandry and fishery and value of all supporting service activities conducted in production of agriculture, forestry, animal husbandry and fishery, one of the indicators of internal collaboration within the primary industry which reflects the major development condition of all industries within the primary industry and offers solid foundation for orderly development of the primary industry.

\subsubsection{Total Power of Agricultural Machinery}

Total power of agricultural machinery refers to the sum of power of all varieties of power generating machinery used in production of agriculture, forestry, animal husbandry and fishery, including farming machinery, agricultural irrigation and drainage machinery, harvesting machinery, agricultural transport machinery, plant protection machinery, animal husbandry machinery, forestry machinery, fishery machinery and other agricultural machinery (power of internal combustion engine is calculated by concerting the horsepower into watt and power of electric motor is calculated by converting the power into watt). This indicator is selected mainly to reflect degree of modernization of agricultural machinery in this region and level of farmers in applying modern technology. Improvement of farmers' quality in applying agricultural science is helpful for modern agricultural development and optimization and upgrading of agricultural industrial structure in Dujiangyan and lays the agricultural foundation for collaborative and interactive development of the primary industry and the tertiary industry.

\subsubsection{Income of Tourism}

As one of the industries in the tertiary industry, namely, as one of the service industries to improve scientific and cultural level and quality of residents, tourism plays an extremely important role in Dujingyan City and has become a leading industry in Dujiangyan. Developmental condition of tourism affects developmental scale and speed of the tertiary industry. Furthermore, such tourism products as rural tourism and agricultural and ecological tourism have become an important approach to resolving the problem of increasing farmers' income and their employment and are an indispensable indicator in studying collaborative development of the primary industry and the tertiary industry.

\subsubsection{Retail Sales of Consumer Goods}

Retail sales of consumer goods can be classified into income of wholesale and retail, income of housing and catering and other income from the perspective of industry. This paper mainly selects income of wholesale and retail and income of housing and catering to manifest that it is these two items of income that occupy the large majority of the total retail sales of consumer goods, up to more than $90 \%$.

\subsubsection{Income of Post and Telecommunication}

As a matter of fact, post and telecommunication is similar to housing and catering in that both of these two industries serve for circulation and both of these two industries balance developmental level of the tertiary industry from the perspective of structure and coordination.

\subsubsection{Output Value of Finance and Insurance and Amount of Investment in Real Estate}

Finance and insurance and real estate are industries that serve for production and living and that balance the developmental level of the tertiary industry from the perspective of structure and coordination.

\subsection{Source of Data}

According to study in this paper and requirement of the model, data about degree of systematic collaboration between the primary industry and the tertiary industry are calculated with the collaboration model of the system. Data about the 16 indicators are directly selected from raw data in "Sichuan Statistical Yearbook", "Chengdu Statistical Yearbook" and "Statistical Bulletin about National Economy and Social Development in Dujiangyan” from 1998 to 2009. Data are shown as in Table 2:

$<$ Table 2 about here>

\subsection{Calculation of Grey Relevancy}

We calculate and get the relevancy of each indicator and their degree of collaboration of the 16 indicators according to the step to get the grey correlation. For the calculation result, we select four digits after the decimal point:

$$
r_{01}=\frac{1}{N} \sum_{i=1}^{N} r\left(x_{0}(k), x_{i}(k)\right)=0.9460 \quad r_{02}=\frac{1}{N} \sum_{i=1}^{N} r\left(x_{0}(k), x_{i}(k)\right)=0.9473
$$




$$
\begin{array}{ll}
r_{03}=\frac{1}{N} \sum_{i=1}^{N} r\left(x_{0}(k), x_{i}(k)\right)=0.9381 & r_{04}=\frac{1}{N} \sum_{i=1}^{N} r\left(x_{0}(k), x_{i}(k)\right)=0.9540 \\
r_{05}=\frac{1}{N} \sum_{i=1}^{N} r\left(x_{0}(k), x_{i}(k)\right)=0.9808 & r_{06}=\frac{1}{N} \sum_{i=1}^{N} r\left(x_{0}(k), x_{i}(k)\right)=0.9712 \\
r_{07}=\frac{1}{N} \sum_{i=1}^{N} r\left(x_{0}(k), x_{i}(k)\right)=0.9631 & r_{08}=\frac{1}{N} \sum_{i=1}^{N} r\left(x_{0}(k), x_{i}(k)\right)=0.9674 \\
r_{09}=\frac{1}{N} \sum_{i=1}^{N} r\left(x_{0}(k), x_{i}(k)\right)=0.9576 & r_{10}=\frac{1}{N} \sum_{i=1}^{N} r\left(x_{0}(k), x_{i}(k)\right)=0.9605 \\
r_{11}=\frac{1}{N} \sum_{i=1}^{N} r\left(x_{0}(k), x_{i}(k)\right)=0.9577 & r_{12}=\frac{1}{N} \sum_{i=1}^{N} r\left(x_{0}(k), x_{i}(k)\right)=0.7298 \\
r_{13}=\frac{1}{N} \sum_{i=1}^{N} r\left(x_{0}(k), x_{i}(k)\right)=0.9722 & r_{14}=\frac{1}{N} \sum_{i=1}^{N} r\left(x_{0}(k), x_{i}(k)\right)=0.9769 \\
r_{15}=\frac{1}{N} \sum_{i=1}^{N} r\left(x_{0}(k), x_{i}(k)\right)=0.9733 & r_{16}=\frac{1}{N} \sum_{i=1}^{N} r\left(x_{0}(k), x_{i}(k)\right)=0.9519
\end{array}
$$

$r_{01}$ and $r_{16}$ respectively refer to relevancy of the following indicators with the indicator of collaboration: ratio of value added of the primary industry to GDP, ratio of employees in the primary industry, ratio of amount of fixed capital formation in the primary industry, agricultural output value, forestry output value, animal husbandry output value, fishery output value, total power of agricultural machinery, ratio of value added of the tertiary industry to GDP, ratio of employees in the tertiary industry, ratio of amount of fixed capital formation in the tertiary industry, amount of investment in real estate, income of tourism, retail sales of consumer goods, income of post and telecommunication and income and expenditure of finance and insurance.

$<$ Table 3 about here $>$

\section{Conclusion and Countermeasures}

\subsection{Conclusion}

From Table 3, it can be discovered that the above 16 indicators have great influences on collaborative development of the primary industry and the tertiary industry in Dujiangyan. Forestry has the greatest influence on collaborative development of the primary industry and the tertiary industry in Dujiangyan, with a relevancy up to 0.9808. Second to forestry is wholesale and retail industry and housing and catering industry, with a relevancy of 0.9769. It is real estate industry that has the smallest influence on collaborative development of the primary industry and the tertiary industry, with a relevancy of 0.7289 . All the other 15 indicators have a relevancy higher than 0.93 except for real estate industry.

\subsection{Countermeasures}

\subsubsection{To Continue to Vigorously Develop Agriculture}

Table 3 indicates that, agriculture has a relatively great influence upon collaborative development of the primary industry and the tertiary industry in Dujiangyan City. Considering the internal industrial structure of agriculture, it can be found that the relevancy of collaborative development of forestry and the tertiary industry is up to 0.9808 , relevancy of animal husbandry is 0.9712 , relevancy of fishery is 0.9631 and relevancy of agriculture (mainly plantation) is 0.9540 . For the time being, we gave to vigorously develop characteristic and superior industries, strengthen construction of bases for characteristic and superior forestry industries, such as mangnolia officinalis and Chinese gooseberry, etc., develop such fishery industries as live pig and cold water fish, etc., enlarge the promoting force of the 100,000 mu of modern ecological and agricultural cluster areas in Dujiangyan City and develop plantation and rural tourism in an overall way.

\subsubsection{To Facilitate Development of Tourism}

In Table 3, relevancy of wholesale and retail industry and housing and catering industry with industrial collaboration is ranked the second, indicating that perfect wholesale and retail industry and housing and catering industry are able to facilitate collaborative development of the primary industry and the tertiary industry. Development of tourism also has 
important promoting effects on collaboration between the primary industry and the tertiary industry, with a relevancy of 0.9722 with collaborative development of the primary industry and the tertiary industry. Wholesale and retail industry and housing and catering industry have strong relevance with development of tourism. Hence, development of tourism in Dujiang City is of similar significance to collaborative development of the primary industry and the tertiary industry. We should pay special attention to development of rural tourism in development of tourism in Dujiangyan. The key to development of rural tourism lies in standardizing behaviors of rural tourism and building a brand of rural tourism.

\subsubsection{To Enhance Employment Rate of the Primary Industry and the Tertiary Industry}

High employment rate of the primary industry and the tertiary industry is able to facilitate collaborative development of the primary industry and the tertiary industry in Dujiangyan City. From Table 3, it can be found that relevancy of employment rate of the tertiary industry with collaborative development of the primary industry and the tertiary industry is up to 0.9605 and relevancy with the primary industry is 0.9473 . Considering the status quo of development of the tertiary industry in Dujiangyan City, the tertiary industry has strong ability to absorb employment of the vast majority of labor force and absorb transferred labor force in agriculture and industry. An important point to enhance employment rate in the primary industry and the tertiary industry is to develop rural tourism. To make full use of characteristic and superior industries in Dujiangyan City and to develop rural tourism in new countryside construction is an important breakthrough to enhance employment rate in the primary industry and the tertiary industry.

\subsubsection{To Enlarge Investment in the Primary Industry and the Tertiary Industry}

It can be discovered from Table 3 that relevancy of total power of agricultural machinery, ratio of amount of fixed capital formation in the tertiary industry and ratio of amount of fixed capital formation in the primary industry with collaborative development of the primary industry and the tertiary industry in Dujiangyan is respectively 0.9674, 0.9577 and 0.9381 . Thus, it can be seen that investment in the primary industry and the tertiary industry is of great significance to collaborative development of the primary industry and the tertiary industry. Currently, the primary task is to enhance agricultural mechanization level, realize economy of scale in agriculture and, meanwhile, enlarge investment in the primary industry and the tertiary industry.

\section{References}

An, S. (2007). Relying on Coordination of the Three Industries to Promote Economic Development. Chinese Cadres Tribune, (12):43-45.

Deng, J. (1999). Grey Control System. Huazhong University of Science and Technology Press.

Table 1. Evaluation indicator system in collaborative development of the primary industry and the tertiary industry in Dujiangyan City

\begin{tabular}{|c|c|c|c|}
\hline Target level & Factor level & Indicator & Explanation \\
\hline \multirow{8}{*}{ 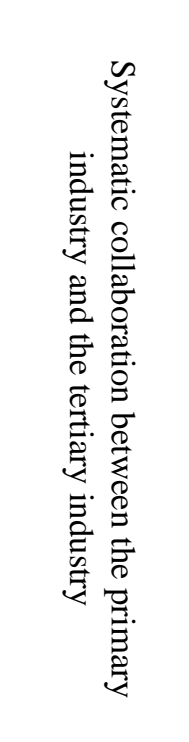 } & \multirow{8}{*}{ 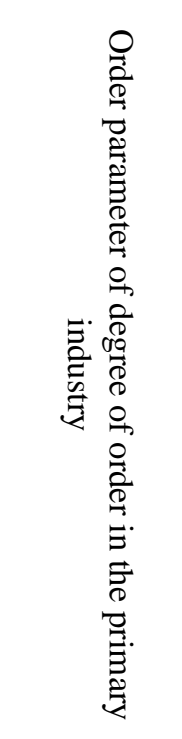 } & $\begin{array}{l}\text { Ratio of value added of the } \\
\text { primary industry to GDP }\end{array}$ & \\
\hline & & $\begin{array}{l}\text { Ratio of employees in the } \\
\text { primary industry }\end{array}$ & \\
\hline & & $\begin{array}{l}\text { Ratio of investment of fixed } \\
\text { capital in the primary } \\
\text { industry }\end{array}$ & \\
\hline & & $\begin{array}{l}\text { Total agricultural output } \\
\text { value }\end{array}$ & Output value of plantation \\
\hline & & Total forestry output value & \\
\hline & & $\begin{array}{l}\text { Total animal husbandry } \\
\text { output value }\end{array}$ & \\
\hline & & Total fishery output value & \\
\hline & & $\begin{array}{c}\text { Total power of agricultural } \\
\text { machinery }\end{array}$ & \\
\hline
\end{tabular}




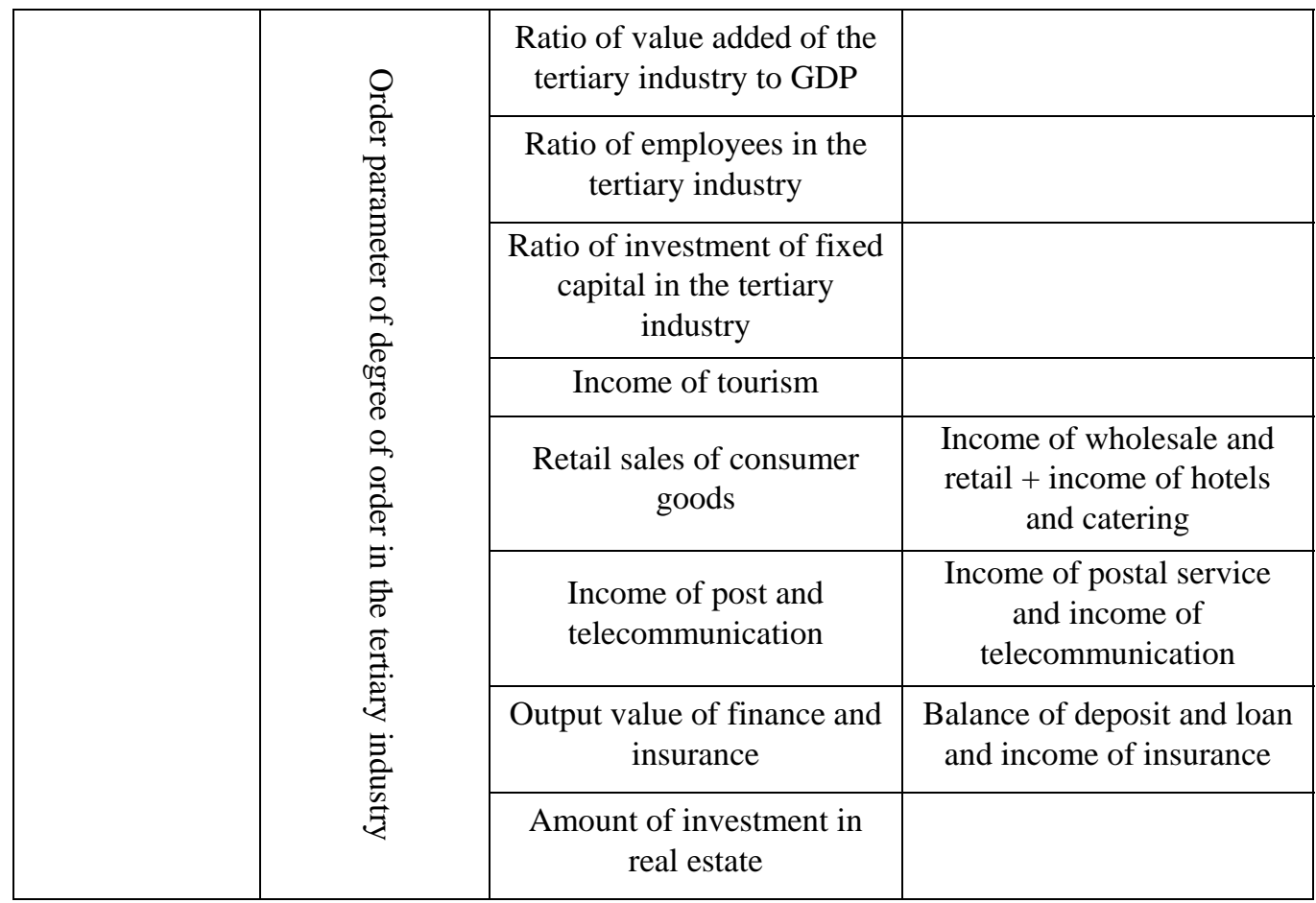

Table 2. Raw data for grey correlation analysis

\begin{tabular}{|c|c|c|c|c|c|c|}
\hline Year & 1998 & 1999 & 2000 & 2001 & 2002 & 2003 \\
\hline Degree of collaboration & 0.0920 & 0.0583 & 0.1744 & 0.2124 & 0.2531 & 0.0999 \\
\hline Ratio of value added of the primary industry to GDP & 0.2300 & 0.2173 & 0.1951 & 0.1583 & 0.1468 & 0.1248 \\
\hline Ratio of employees in the primary industry & 0.4849 & 0.4573 & 0.4557 & 0.4521 & 0.3959 & 0.3631 \\
\hline Ratio of amount of fixed capital formation in the primary industry & 0.2239 & 0.1575 & 0.1164 & 0.0712 & 0.0806 & 0.0744 \\
\hline Agricultural output value & 8.9200 & 8.5600 & 8.2400 & 7.8700 & 8.2400 & 7.5400 \\
\hline Forestry output value & 0.2600 & 0.2100 & 0.3900 & 0.8100 & 0.8600 & 0.4200 \\
\hline Animal husbandry output value & 3.5800 & 3.2600 & 4.5700 & 5.1800 & 5.5000 & 6.4300 \\
\hline Fishery output value & 0.2400 & 0.1900 & 0.1700 & 0.2000 & 0.2100 & 0.2400 \\
\hline Total power of agricultural machinery & 9.4700 & 10.6700 & 11.3800 & 11.5900 & 11.8500 & 12.2100 \\
\hline Ratio of value added of the tertiary industry to GDP & 0.4339 & 0.4379 & 0.4448 & 0.4557 & 0.4514 & 0.4340 \\
\hline Ratio of employees in the tertiary industry & 0.3264 & 0.3306 & 0.3319 & 0.3200 & 0.3511 & 0.3614 \\
\hline Ratio of amount of fixed capital formation in the tertiary industry & 0.5809 & 0.6245 & 0.6277 & 0.7582 & 0.7296 & 0.6921 \\
\hline Amount of investment in real estate & 0.6852 & 1.0278 & 1.8500 & 3.9800 & 5.7500 & 6.4000 \\
\hline Income of tourism & 8.2000 & 8.1400 & 9.1400 & 10.1000 & 11.2000 & 8.3000 \\
\hline Retail sales of consumer goods & 16.8900 & 19.1800 & 21.9600 & 26.2000 & 29.6600 & 31.6000 \\
\hline Income of post and telecommunication & 0.8000 & 1.0200 & 1.2100 & 1.3900 & 1.7600 & 0.9900 \\
\hline Income and expenditure of finance and insurance & 60.2100 & 66.2200 & 76.5600 & 82.3500 & 85.1100 & 108.8100 \\
\hline Year & 2004 & 2005 & 2006 & 2007 & 2008 & 2009 \\
\hline Degree of collaboration & 0.1919 & 0.3267 & 0.3434 & 0.3805 & 0.2078 & 0.2201 \\
\hline Ratio of value added of the primary industry to GDP & 0.1181 & 0.1409 & 0.1300 & 0.1325 & 0.1959 & 0.1360 \\
\hline Ratio of employees in the primary industry & 0.3508 & 0.3247 & 0.3108 & 0.2888 & 0.2100 & 0.1981 \\
\hline
\end{tabular}




\begin{tabular}{|c|c|c|c|c|c|c|}
\hline Ratio of amount of fixed capital formation in the primary industry & 0.0705 & 0.0567 & 0.1053 & 0.0527 & 0.0282 & 0.0243 \\
\hline Agricultural output value & 8.1200 & 8.0900 & 8.4800 & 9.9700 & 9.4400 & 9.5900 \\
\hline Forestry output value & 0.4300 & 0.5000 & 0.5400 & 0.9300 & 0.6000 & 0.6400 \\
\hline Animal husbandry output value & 7.8100 & 8.7500 & 9.6100 & 12.8500 & 14.0500 & 16.3800 \\
\hline Fishery output value & 0.2800 & 0.3200 & 0.3900 & 0.5800 & 0.2500 & 0.4700 \\
\hline Total power of agricultural machinery & 15.4000 & 15.3300 & 15.2300 & 16.1800 & 16.4800 & 18.9800 \\
\hline Ratio of value added of the tertiary industry to GDP & 0.5663 & 0.5033 & 0.5063 & 0.4983 & 0.4020 & 0.5252 \\
\hline Ratio of employees in the tertiary industry & 0.3581 & 0.3841 & 0.4007 & 0.4087 & 0.5125 & 0.5357 \\
\hline Ratio of amount of fixed capital formation in the tertiary industry & 0.6555 & 0.5315 & 0.4858 & 0.4798 & 0.7717 & 0.8042 \\
\hline Amount of investment in real estate & 9.3200 & 12.0500 & 19.5000 & 26.7000 & 14.3500 & 40.9000 \\
\hline Income of tourism & 13.0000 & 15.1400 & 19.8300 & 33.3300 & 18.0000 & 42.0800 \\
\hline Retail sales of consumer goods & 36.0000 & 41.0400 & 43.5300 & 50.7800 & 30.1700 & 50.9500 \\
\hline Income of post and telecommunication & 3.0600 & 4.5200 & 3.8600 & 3.3900 & 2.2600 & 3.3000 \\
\hline Income and expenditure of finance and insurance & 118.1400 & 136.2600 & 166.1000 & 182.5000 & 347.3600 & 607.8200 \\
\hline
\end{tabular}

Table 3. Sequencing of all indicators and relevancy of collaboration

\begin{tabular}{|c|c|c|}
\hline Indicator & Relevancy (R) & Ranking \\
\hline $\begin{array}{c}\text { Forestry output value } \\
\text { catering) }\end{array}$ & 0.9808 & 2 \\
\hline $\begin{array}{c}\text { Retail sales of consumer goods (wholesale and retail, housing and } \\
\text { Income of post and telecommunication }\end{array}$ & 0.9769 & 3 \\
\hline Income of tourism & 0.9722 & 4 \\
\hline Animal husbandry output value & 0.9712 & 6 \\
\hline Total power of agricultural machinery & 0.9674 & 7 \\
\hline Fishery output value & 0.9631 & 8 \\
\hline Ratio of employees in the tertiary industry & 0.9605 & 10 \\
\hline Ratio of amount of fixed capital formation in the tertiary industry & 0.9577 & 11 \\
\hline Ratio of value added of the tertiary industry to GDP & 0.9576 & 12 \\
\hline Agricultural output value & 0.9540 & 13 \\
\hline Income and expenditure of finance and insurance & 0.9519 & 14 \\
\hline Ratio of employees in the primary industry & 0.9473 & 15 \\
\hline Ratio of value added of the primary industry to GDP & 0.9460 & 16 \\
\hline Ratio of amount of fixed capital formation in the primary industry & 0.9381 & \\
\hline Amount of investment in real estate & 0.7298 & \\
\hline
\end{tabular}




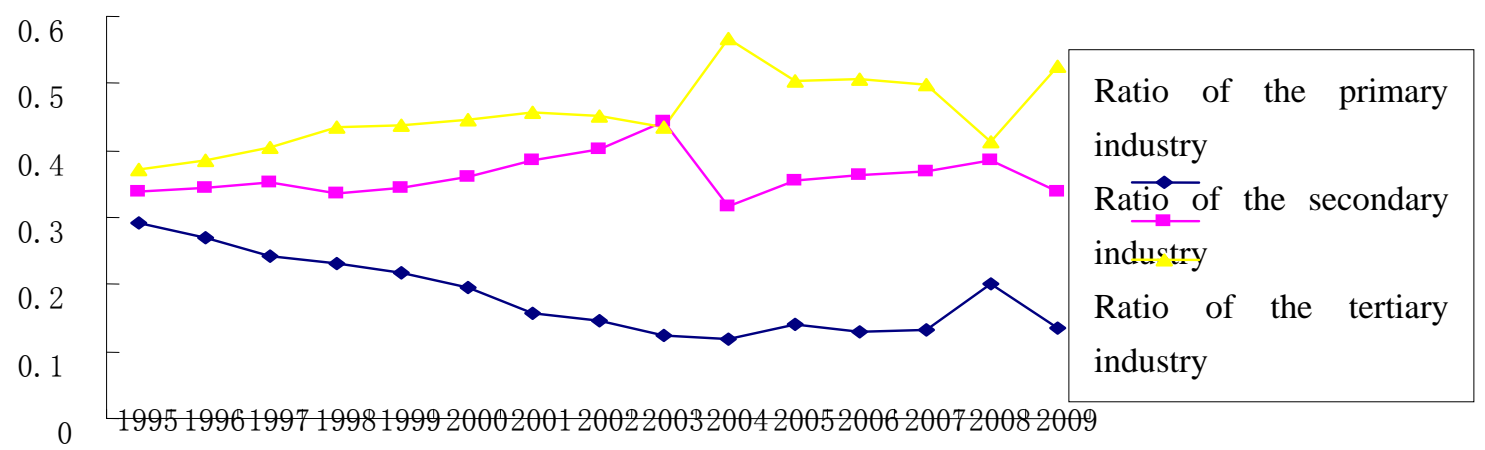

Figure 1. Contrast of industrial output from 1995 to 2009 in Dujiangyan City 